\title{
The American Marketing Association's 2004 Definition of Marketing: Perspectives on Its Implications for Scholarship and the Role and Responsibility of Marketing in Society
}

\author{
Gregory T. Gundlach
}

In 2004, the American Marketing Association announced a new definition of marketing. This special section examines the implications of this definition for (1) scholarship_in particular, scholarship that addresses "marketing and society"-and (2) the role and responsibility of marketing in society.

T he importance of a definition, including for the field of marketing, cannot be overstated. Standing alone, a definition defines the scope and content of that which is defined, fixing its boundaries and describing its subject matter. A formal definition is an authoritative statement of meaning or significance that attaches to and explains the nature and essential qualities of that which is defined. In application, a definition provides clarity and direction, making clear what might be otherwise obscure and indefinite. A consensus definition aids in communication and understanding and helps discern and distinguish the subject matter to which it applies (Gundlach 2006).

When a definition is applied to a societal institution and professional discipline, such as marketing, it also has important practical and symbolic implications (Zinkhan and Williams 2007). In practical terms, a sufficiently inclusive definition can embrace and inform conceptions of marketing as a phenomenon to be studied by scholars and students, as well as more narrow formulations of marketing as a managerial function and process to be performed by firms and practicing professionals. A definition of marketing can be developed that sets boundary conditions, aids in the identification of critical questions, and facilitates communication with and imparts understanding to others on behalf of those who study it. The same definition can also be crafted to imply certain qualifications, competencies, and conduct by those who practice it. Importantly, an encompassing definition can include and inform each of these qualities, offering both scholars and practitioners, and those with whom they wish to communicate, a clear understanding of the term "marketing." A sufficiently prescriptive definition can also serve to promote the nature, role, and legitimacy of marketing in the eyes of others, including scholars and practitioners in other disciplines and members of society at large (Zinkhan and Williams 2007).

Gregory T. Gundlach is Visiting Eminent Scholar and Professor of Marketing, Coggin College of Business, University of North Florida, and Senior Research Fellow, American Antitrust Institute (e-mail: Ggundlac@unf.edu).

\section{The American Marketing Association's 2004 Definition of Marketing}

Since 1935, the American Marketing Association (AMA) has offered to both practitioners and academics its version of the definition of marketing. The first official definition of marketing was adopted in 1935 by the National Association of Marketing Teachers, a predecessor of AMA. ${ }^{1}$ With only slight revision, this definition was formally adopted by the AMA in 1948 and again in 1960, when the AMA revisited the definition and decided against changing it. ${ }^{2}$ This original definition stood for 50 years, until it was revised in 1985. ${ }^{3}$ In 2004, the AMA announced a new definition of marketing:

Marketing is an organizational function and a set of processes for creating, communicating and delivering value to customers and for managing customer relationships in ways that benefit the organization and its stakeholders.

The new definition was unveiled at AMA's Summer Educators' Conference in Boston in August 2004 (Keefe 2004). At the time, the AMA reported that it incorporated the contributions of many marketers from around the world, both academics and practitioners.

\section{Reactions, Commentary, and Discourse}

Almost immediately, the AMA's new definition brought forth reaction and commentary by members of the academic

1The AMA began its existence on January 1, 1937. The association was formed by the merging of the American Marketing Society and the National Association of Marketing Teachers. The preamble of the AMA's constitution and bylaws included the 1935 definition of marketing developed and adopted by the National Association of Marketing Teachers. This definition defined marketing as "those business activities involved in the flow of goods and services from production to consumption" (AMA 1937).

2The slightly revised definition read, "[T]he performance of business activities that direct the flow of goods and services from producers to consumers" (AMA Committee on Definitions 1960, p. 15).

3AMA's 1985 definition defined marketing as "the process of planning and executing the conception, pricing, promotion, and distribution of ideas, goods, and services to create exchanges that satisfy individual and organizational goals." 
community and, in particular, those within the area of scholarship known as "marketing and society."4 A particular focus of discourse by members of this community was concern with the definition's implications for (1) scholarship_-in particular, scholarship addressing marketing and society_-and (2) the role and responsibility of marketing in society. Some reacted to these concerns as partly the result of a lack of transparency in the process associated with the definition's development (see Dunlap 2006; Ringold and Weitz 2007). However, others viewed these concerns as more substantive in nature and reflective of larger and more basic challenges for the discipline (see Gundlach 2006; Wilkie 2006).

Continuing discourse surrounding the definition and mounting concerns for its implications subsequently galvanized into several special sessions focusing on the definition and participated in by scholars in the field. 5 These special sessions were held at major AMA conferences, including the 2005 Marketing and Public Policy Conference (Gundlach 2005), the 2006 AMA Winter Educators' Conference, and the 2007 AMA Summer Educators' Conference, at which a plenary session was convened. ${ }^{6}$ Commentary on the nature of marketing, including consideration of AMA's 2004 definition, also took place in other forums. ${ }^{7}$ Questions and concerns about the definition subsequently

${ }^{4}$ Wilkie and Moore (2003) identify six areas of scholarship that address topics in marketing and society, including public policy and marketing, macromarketing, consumer interest economics, social marketing, marketing ethics, and international consumer policy, and these have been adopted by others (see Gundlach, Block, and Wilkie 2007). As Wilkie and Moore (2003, p. 140) describe,

[A]mong the six primary groups, there are people who wish to focus on social change and help those managing these efforts (social marketing), others who wish to focus on helping corporate marketers make more ethical decisions (marketing ethics), and still others who focus on the aggregate marketing system and its impacts on economic development, quality of life, or other issues (macromarketing). Another set of researchers focuses either on helping government decision makers and marketers devise more efficient and effective regulatory policies or legislation or on broader issues involving the roles for government, marketers, and the legal system (public policy and marketing). Furthermore, some people are approaching problems within different cultural and political contexts (international consumer policy), and some are approaching with different aims and methods (consumer interest economics).

5The following scholars (in alphabetical order) participated in one or more of the AMA special sessions: Gregory T. Gundlach, University of North Florida; Shelby D. Hunt, Texas Tech University; David G. Mick, University of Virginia; Elizabeth S. Moore, University of Notre Dame; Debra J. Ringold, Willamette University and AMA representative; Jagdish N. Sheth, Emory University; Clifford J. Shultz II, Arizona State University; Rajendra S. Sisosdia, Bentley College; Barton A. Weitz, University of Florida; William L. Wilkie, University of Notre Dame; and George M. Zinkhan, University of Georgia.

${ }^{6}$ Although originally designated as the plenary session, at the suggestion of the AMA Academic Council, the session's status was changed before the conference to that of a special session.

${ }^{7}$ For example, a symposium titled "Does Marketing Need Reform?" hosted by Jagdish Sheth and Raj Sisodia and sponsored by The McCallum Graduate School of Business, Bentley College, was held on August 9, 2004, in Boston. Essays based on the symposium appear in a book by the same title and edited by Sheth and Sisodia (2006). Many contain commentary on AMA's 2004 definition (e.g., see essays by Grove, John, and Fisk 2006; Gundlach 2006; Wilkie 2006). In addition, commentary may also be found in the work of Lusch and Vargo (2006) (see, e.g., essays by Laczniak 2006; Lehmann 2006; Levy 2006; Wilkie and Moore 2006). led to an invitation by Editor Ron Hill for articles addressing the AMA's new definition of marketing and providing perspectives on its implications for scholarship and the role and responsibility of marketing in society to be considered for inclusion in this special section of the Journal of Public Policy \& Marketing.

\section{Overview of the Special Section}

Articles appearing in the special section include essays by scholars in the field of marketing who participated in the special sessions and others who submitted essays in response to the published call for papers. ${ }^{8}$ Each author's contributions benefited from the thoughtful input and suggestions of the $J P P \& M$ editorial review board and other reviewers commissioned for the section. In total, the essays provide considerate and, at times, provocative commentary on AMA's 2004 definition of marketing as well as unique perspectives on its implications for scholarship and the role and responsibility of marketing in society.

\section{Themes and Commentary}

Although the essays represent various perspectives and are articulated in different ways, several common themes may be identified. I detail these in the following subsections.

\section{Domain and Perspective of Marketing}

A key theme elaborated on is that in characterizing marketing as an "organizational function and a set of processes," the AMA's 2004 definition is overly narrow in its domain and perspective. Several contributors opine that the marketing definition excludes many other institutions, actors, individuals, processes, and important perspectives known to be part of the aggregate marketing system and the focus of considerable academic scholarship in marketing, both past and present. For example, Zinkhan and Williams (2007) find that the "new definition is needlessly narrow in scope" (p. 285), observing that it "appears to assign marketing to the restricted confines of an organization" (p. 285). Wilkie and Moore (2007) point out that the "[t]he 2004 definition ... delimit[s] marketing with its singular focus on the individual organization acting alone" (p. 270) and that "the 2004 definition is one of 'marketing management,' not of the entire field or discipline of marketing" (p. 270). Hunt (2007, p. 281) similarly finds that the definition "fails to incorporate explicitly the view that marketing is more than a managerial technology within organizations. That is, it fails to acknowledge the existence and roles of marketing institutions and marketing systems in society."

From Shultz's (2007, p. 293) perspective, AMA's 2004 definition is "too microscopic," given its focus on marketing management versus all of marketing. Similarly, Zinkhan and Williams (2007, p. 287) observe that "[a] major shortcoming in this regard is the new definition's

8In addition to these invited contributors, AMA, as the source of the definition, was also invited to participate in the special section. At first, the AMA formally accepted this invitation, but then later declined. Insights as to the rationale for this decision are offered by Ringold and Weitz (2007), who are participating in the special section in their roles as former chairpersons of the AMA board of directors. 
focus on marketing as a management practice rather than recognizing it as a broader societal phenomenon." Wilkie and Moore (2007, p. 273) agree, noting that the definition possesses "a glaring deficiency with regard to its restriction in recognizing only marketing management." Wilkie and Moore go on to point out (p. 270) that an important implication of "such a conceptual limitation for the field... [is that] [f]irst, some important broader questions can go unasked (and unanswered) precisely because the managerial perspective simply never needs to consider these questions to act in a single firm's best interests. Second, this narrow conception may be becoming so dominant in the field that it is foreclosing other worthwhile directions for thought development."

Lusch (2007, p. 261) contends that "in terms of the domain of marketing, the definition needs to recognize marketing more explicitly as a societal process."9 Wilkie and Moore (2007, p. 273) "stress that it is a root responsibility of academia (including institutions, such as the AMA) to place a field of study into proper perspective." According to Hunt (2007, p. 280), "[s]ince the founding of the marketing discipline by scholars such as Arch Shaw, Ralph S. Butler, and L.D.H. Weld in the early 1900s, the study of marketing systems and institutions has been central to marketing thought." In this respect, Hunt (p. 281) advances that in addition to "[h]ow marketing is conducted and ought to be conducted within organizations in society,... [i]t is also important how marketing is conducted and ought to be conducted among organizations in society."

Relatedly, Zinkhan and Williams (2007, p. 285) question "why marketing should be principally positioned as an organizational function rather than a broader phenomenon involving multiple aspects of society," finding that "[t]here are many instances in which individuals, rather than organizational entities, engage in the act of marketing." Wilkie and Moore (2007, p. 273) similarly opine that "[i]t is important that the official definition for the field of marketing explicitly includes the societal domain and the remarkable marketing systems that characterize the workings of our field." Finally, Ringold and Weitz (2007, p. 255) conclude that "an official definition ... [that] acknowledges marketing activity in the public, private, and nonprofit sectors and recognizes activity and impacts at the individual, organizational, and societal levels may serve to improve the collective understanding and practice of marketing. This is an opportunity we should fully exploit."

\section{Marketing's Role and Responsibility in Society}

In addition to concerns regarding the domain and perspective of the AMA's 2004 definition of marketing, some con-

\footnotetext{
9In heading up the effort to revise the 1985 AMA definition, Lusch (2007, p. 265) developed and proposed the following definition as a candidate for the new 2004 AMA definition: [M]arketing is the adaptive process, in society and organizations, of collaborating to communicate, create, provide, and sustain value for customers through exchange relationships while meeting the needs of diverse stakeholders. As Lusch (2007, p. 265) notes, although "[the] definition was pluralistic and thus could be used at any level of aggregation, from the micro to the most aggregate of marketing systems,... [i]n the final analysis, the definition the AMA adopted included [only] explicit mention of value and stakeholders."
}

tributors to the special section question whether, in the face of an increasingly complex and challenging world, the definition addresses marketing's role and responsibility in society in ways that adequately inform and provide guidance to marketing practitioners and others. For example, Hunt (2007, p. 281) observes that though it is missing from the 2004 AMA definition, "[h]ow marketing is conducted and ought to be conducted within [and among] organizations in society is an important component of marketing." Mick (2007, p. 289) finds that the new "definition of marketing by the $[\mathrm{AMA}] \ldots$ ignores marketers' moral responsibility for the socioecological conditions of the world." Mick further observes (p. 291) that "[i]f marketing is to live up to its maximum potential, simultaneously with its socioecological obligations, and also become more genuinely appreciated by the public, the goal of marketing, as with wisdom itself, must be the common good."

Hunt (2007, p. 280) contends "that marketers have a responsibility to understand marketing systems in society (and societies) from both normative and positive perspectives," and Wilkie and Moore (2007, p. 270) note that the failure to do this "has brought about some serious oversights in terms of the scope and role of marketing in the world." Observing that "there are marketing issues in the world that are larger than the problems of a single organization," Wilkie and Moore $(2007$, p. 271) point out that the 2004 definition's "singular focus" fails "to recognize the competitive nature of the marketing system" (p. 270), does not "consider and address major societal and public policy issues" (p. 270), "overlooks the marketing system's [versus individual firm's] interactions with consumers" (p. 271), and "inadvertently understates the scope and importance of marketing" (p. 272). Wilkie and Moore (2007, p. 271) observe that "these characteristics make it difficult to equate the best interests of a marketer in each firm with each consumer's best interest" and that of society's overall.

Wilkie and Moore (2007, p. 272) also note that the narrow focus and perspective of marketing contained in the 2004 definition has the inadvertent effect of "support[ing] a suppressive effect on scholarly inquiry in marketing and society." In this regard, in detailing marketing's responsibilities to the academy, society, students, and practitioners, Hunt (2007, p. 278) observes that "marketing academe owes society its best efforts toward the goal of objectivity" and that "academics have a responsibility to keep in mind that society is the ultimate client for the knowledge that academics produce, and marketing practitioners are intermediate clients."

Regarding this objectivity and responsibility, Wilkie and Moore (2007, p. 270) suggest that the "greatest risk of equating the field of marketing solely with the managerial decisions being made inside organizations is that the goals and conduct of those organizations are also being adopted by marketing thinkers but without any external appraisal." As they describe further (pp. 270-72), "[t]his leads to something akin to a blanket approval regarding the reality of what the marketing world in total is undertaking" and "adds weight to the difficulties faced by people who believe that much more educational and research attention needs to be given to the examination of marketing's impacts in society." Ringold and Weitz (2007, p. 255), however, disagree, 
contending that " $[\mathrm{t}]$ he suggestion that the 2004 AMA definition will somehow constrain those committed to a different view insults scholars and practitioners whose conceptualization of marketing is at odds with the official one."

In general, however, contributors agree, as Wilkie and Moore (2007, p. 273) point out, that "[t]he impacts of marketing in the world are a legitimate concern for scholarship in our field." Ringold and Weitz (2007, p. 255) similarly note that "an official definition that fosters positive description and normative evaluation ... may serve to improve the collective understanding and practice of marketing." Lusch (2007, p. 267) concludes that "[m]y sense is that if we get everything else 'right' but fail to develop a coherent and compelling body of thought regarding the aggregate marketing system, we will have failed society and ourselves as a profession." He further notes (p. 267) that "[i]f the community of marketing scholars and their professional associations does not take a lead role in studying and researching marketing as a societal process and institution, this type of research will be left exclusively to scholars outside marketing and, most likely, outside business."

\section{Other Commentary}

To a lesser extent and in addition to the preceding themes, other commentary about AMA's definition is also offered within the special section, including both positive assessments of its nature and implications and additional concerns. For example, citing a story appearing in Marketing News, Ringold and Weitz (2007, p. 253) note that "[s]ome marketing academics and practitioners agree that the 2004 definition reflects the current practice and study of marketing better than the 1985 definition (Keefe 2004)." Zinkhan and Williams (2007, pp. 284-85) also "commend the motivation for continuous improvement and the effort undertaken in its creation," finding that the "new version has positive merits worth noting." Wilkie and Moore (2007, p. 273) similarly observe that "[t]he 2004 definition has positive elements." Lusch (2007, p. 261) "believe[s] that it is an improvement over the 1985 definition." Sheth and Ulsay (2007, pp. 304-305) "applaud the [definition's] shift away from the exchange paradigm" toward value creation. Shultz (2007, p. 293) and others (as previously noted) find that the new definition is "useful to the practice of marketing management." To this end, Wilkie and Moore (2007) "agree that the conception of marketing as a strategic and tactical activity undertaken within individual organizations holds a professional appeal for marketing managers and is a reasonable view for academics to use when appropriate" (p. 270) and that "the 2004 effort [is] actually a definition of "marketing management"" (p. 269).

The contributors to the special section also advance additional concerns about the definition, beyond those already described. This includes commentary addressing the definition's "exclusivity," "clarity," and "communicability" and questions regarding the definition's general "relevance" to practitioners, students, and academics (Hunt 2007). In addition, Zinkhan and Williams (2007) observe concerns for "word choices" and "logical anomalies" in the definition, its adoption of a "production orientation," and its "[isolation] from the past." Wilkie and Moore (2007) similarly find the definition, in conjunction with prior AMA definitions, to "have lost continuity in the field."

\section{Related Insights for Understanding}

Beyond these themes and commentaries, the essays provide readers with additional insights for understanding the AMA's definition and its implications for scholarship and the role and responsibility of marketing in society. These include the AMA's motivations, challenges, and processes associated with development of the definition (Ringold and Weitz 2007), the historical evolution of marketing (Lusch 2007; Zinkhan and Williams 2007), the nature of its definitions (Wilkie and Moore 2007), and the attention to topics by scholars in marketing and society over time (Lusch 2007). Contributors also offer criteria (Zinkhan and Williams 2007), attributes, and frameworks for the development and assessment of superior definitions, including for marketing (Hunt 2007), and they provide perspectives on the role and responsibility of marketing (Mick 2007) and the marketing profession (Hunt 2007) for society (Shultz 2007), students, and practice and the potential impact for society and research of the shift away from exchange as the paradigm of marketing to a value creation and network orientation in marketing (Sheth and Ulsay 2007).

\section{Commentary}

To some, the opinions and viewpoints expressed in the essays may not be viewed as new or different from prior observations offered by others within the field of marketing. Previously, scholars have voiced concern for the marketing discipline's adoption of an increasingly narrow managerial scope and exclusive marketer perspective. As with contributors to the special section, these scholars contend that marketing encompasses a broader domain and involves institutions, actors, and processes in addition to those of the firm. In addition, these scholars call attention to the potential myopia and hazards for both marketing practice and scholarship in adopting an exclusive marketer perspective. They also counsel that assessments and judgments of "what marketing is" and "what marketing is not" should give considerate attention to the role and responsibility of marketing in society.

I contend that various features of modern marketing endow the observations and concerns of both past and present scholars with additional significance and added consequence. However, I argue that modern marketing is responding to these concerns in ways that demonstrate the inclusion of its larger institutions, actors, and processes; perspectives that embrace viewpoints beyond the firm; and considerations that include marketing's role and responsibility in society. I suggest that if a definition of marketing is to reflect modern marketing, it should also describe these features. For the field and, in particular, its scholarship, I describe the benefit of adopting such a definition and the potential consequences that may result if such a definition is not adopted. Finally, I contend that as the leading organization of its kind in marketing, the AMA is the most appropriate institution to offer such a definition and that it should take a leadership role in doing so. I conclude that the essays in the special section provide considerable insight into and 
understanding necessary for accomplishing this result, and I encourage the AMA to adopt the wisdom and vision of its contributors.

\section{Previous Observations of "Marketing"}

Almost 25 years ago, Robert Bartels (1983, pp. 34-35, emphasis added) counseled that viewing marketing as organizationally bound "means that important aspects of total marketing are neglected." By "total" marketing, Bartels was referring to the larger societal institutions, actors, and processes of marketing found beyond the firm. Such sentiments have continued to be voiced over time by others. For example, Kotler and Armstrong (2001, p. 13, emphasis added) observe that " [c]onsumers $d o$ marketing when they search for the goods they need at prices they can afford." Wilkie and Moore (1999, p. 201) go further, suggesting that "[t]here are participants other than marketers in the aggregate marketing system. Organizational customers and ultimate consumers are key players,... and governments provide services intended to facilitate system operations." As with the contributors to the special section, the common observation of these scholars and others is that marketing is more than an organizational function and set of processes, involving institutions and processes beyond the firm.

More than 30 years ago, Tucker (1974) also cautioned against the implications for scholarship that accompanies the adoption of a narrow domain and exclusive marketer perspective. Lamenting at the time over the field's tendency to study consumers from the point of view of the "channel captain," he analogized (p. 31) the adoption of an exclusive marketer perspective to be equivalent to "the ways that fisherman study fish rather than as marine biologists study them." Tucker concluded (p. 31) that studying marketing narrowly and from a single point of view "encourage[s] the sort of myopia common to all specialists" (see also Bazerman 2001). Echoing such concerns, almost ten years later, Anderson (1983, p. 28) described the realities of Tucker's observations, remarking that " $[\mathrm{m}]$ arketing's preoccupation with the concerns of Tucker's 'channel captain' introduces an asymmetry into the study of the phenomenon that can only limit the discipline's perspective and inhibit its attainment of scientific status." This latter result pertains to the field's ability to obtain scientific legitimacy because it is primarily concerned with the interests of only one segment of society; this is a concern for any academic discipline that desires to achieve scientific status (see Kuhn 1962). More recently, Bazerman (2001) has argued for a consumerbased approach to consumer research, describing the "implicit biases" that attend research in consumer behavior that applies a marketer perspective and focuses on the determinants of consumer purchasing. Others (e.g., Mick 2006) have similarly called for such research and have implemented scholarly agendas for such "transformative" research.

Finally, as to marketing's role in and responsibility to society, Bartels (1983, p. 33) counseled long ago that "a standard for judging what is or is not marketing must give consideration to the question of the role of marketing in human society." Indeed, questions regarding marketing's moral and social responsibility have been a mainstay of academic scholarship for some time. More recently, several scholars have observed the need for even greater focus on the societal role and ethical responsibility of marketing in future practice and scholarship (e.g., Laczniak 2006).

\section{Modern Marketing}

Various features of modern marketing suggest that, today, the concerns for marketing described by past and current scholars have additional significance and added consequence. However, modern marketing is responding to these concerns in ways that demonstrate the inclusion of its larger institutions, actors, and processes; perspectives that embrace viewpoints beyond the firm; and considerations that include marketing's role and responsibility in society. If the AMA's definition of marketing is to reflect modern marketing, it should embrace and champion these characteristics.

Various features of modern marketing demonstrate its widening scope, varying perspectives, and increasing role and responsibility in society. For example, the everincreasing globalization of trade yields conditions that result in a broader scope and perspective for marketing (Shultz 2007). Successful marketers recognize the complexity and dynamism of the larger cultural, political, and social institutions; actors and individuals; and processes that make up this global environment. Through technology and other enablers, consumers have also become more global in their sphere of consideration and in how they approach their living and consumption processes. Practitioners and scholars in marketing and related disciplines increasingly recognize these changes and are adopting larger units of analysis and varying perspectives in their approach and study of marketing.

Basic changes in how marketing is approached and studied within this larger and more complex global environment also contribute to a broadened view and perspective for marketing. Consider the paradigmatic recognition in marketing that beyond transactions, relationships play an important role in marketing. This recognition has altered the scope and perspective of marketing from that of exchange involving discrete transactions bound temporally in time and space to relationships occurring over time and across space (Sheth and Ulsay 2007). Similarly, as Vargo and Lusch (2004) observe, marketing is evolving from a state in which value in exchange is the dominant logic to a logic in which both value in exchange and value in use dominate. Such an evolution further expands the necessary scope and perspective of marketing by broadening the concept of value to include individual, firm, stakeholder, and larger societal considerations and viewpoints (Lusch 2007).

The nature of modern marketing has also driven marketing to give greater consideration to its role and responsibility in society. Although consumers, marketers, and society benefit in many ways from the larger global environment of business, they also face greater challenges and are more vulnerable in this setting (Shultz 2007). Similarly, although relational exchange and marketing provides added benefits and, in some ways, dampens the risks of exchange for consumers and marketers, each is ultimately exposed to a greater number of risks and vulnerabilities when exchange 
is consummated over time and across space as part of an ongoing, interdependent relationship than when it is delimited to a single point in time and a particular place in space and involves less interdependence (Sheth and Ulsay 2007). Finally, although foreshadowing significant benefits, the broadened conception of value that is predicted to dominate marketing logic into the future yields more opportunity for conflict, exploitation, and opportunism through its conception to include both value in exchange and value in use and through its encompassment of considerations across individuals, firms, stakeholders, and society (Lusch 2007).

\section{Benefits and Consequences of a Modern Definition of Marketing}

The benefits of a definition that reflects modern marketing include (1) an institution and discipline that is more inclusive of institutions, actors, and processes in society that make up and are affected by it; (2) a field of practice and scholarship that more fully recognizes and appreciates differing perspectives and viewpoints about it; and (3) a world that stands to benefit from a view of marketing that possesses greater sensitivity to its role in society and embraces greater responsibility to its inhabitants. ${ }^{10}$

\section{Scholarship in Marketing}

The consequences of not defining marketing in ways that reflect modern marketing are significant. In other forums, I have noted that these effects are particularly consequential for marketing scholarship (Gundlach 2005, 2006). As with any subject matter, narrowly defining the scope and perspective of marketing is of consequence because it constrains the relevant domain of interest, limits the development and dissemination of knowledge about it, and biases knowledge that is developed and disseminated about it. ${ }^{11}$

In relation to the domain of marketing, and also observed by contributors to the special section, defining marketing as an organizational function and a set of processes describes what is better known as "marketing management."12 Although consistent with a marketer's view of marketing, marketing management does not fully describe the scope of marketing. Beyond specific functions and processes in which organizations and their marketers engage, marketing

\footnotetext{
${ }^{10}$ Although not analyzed, it is difficult to discern any significant costs that are likely to be incurred for the field in defining marketing as something more than that which involves the firm. At a time when marketing has been viewed by some to be increasingly marginalized in its role and influence by movements such as total quality management and supply chain management, what are the disadvantages in defining it to more comprehensively include those involved? Moreover, at a time when those involved in marketing and others affected by marketing are searching for answers to complex economic and social problems in the world, what disadvantages attend its definition to include perspectives beyond that of the firm? Finally, at a time when other business disciplines (e.g., finance, accounting) are attracting greater scrutiny of their practices, what are the disadvantages in defining marketing in a way that more explicitly considers its role and responsibility to others? I contend that the benefits of defining marketing in this way greatly outweigh any costs associated with doing so.

${ }^{11}$ Although acknowledging their significance and similarity, I do not directly elaborate on the consequences for scholarship of not defining marketing in ways that are considerate of its role and responsibility in society.

12Others scholars have observed that prior AMA definitions of marketing are definitions of "marketing management" rather than of marketing (see Kotler and Armstrong 2001).
}

encompasses a much broader domain and alternative perspectives. Marketing includes additional institutions, actors, individuals, and processes in society. From the standpoint of scholarship, circumscribing marketing to activities and processes of the firm and its marketers excludes these relevant participants and their perspectives, thus constraining the relevant domain of interest.

Adoption of a definition that views marketing as an organizational function and a set of processes also has the consequence of limiting the development and dissemination of knowledge about marketing. This consequence exists for the study of any subject when approached narrowly and from a single vantage point. A definition of marketing that views marketing as an organizational function and a set of processes focuses knowledge development and dissemination activities on subjects that address topics and issues of specific interest to the firm and its managers. Other topics and issues of interest to those who view marketing more broadly and from other vantage points are deemphasized. Dissemination of knowledge that is developed from these other vantage points is also adversely affected as increasing emphasis is given to knowledge that aids the firm. Over time, the perception that marketing knowledge is limited only to topics and issues of interest to the marketer ultimately can inhibit the flow of knowledge both within the field and to other fields in which interest in marketing is not similarly circumscribed. Overall, there exists the prospect that knowledge development and dissemination from this larger domain will not be considered "mainstream," leading to the view that such contributions are "outside" marketing. Viewed as not marketing, at the extreme, such endeavors might not be recognized (e.g., published) or rewarded (e.g., tenure) by the discipline or its institutions.

Perhaps the greatest concern in the adoption of a definition that views marketing as an organizational function and a set of processes is that knowledge that is developed and disseminated about marketing might ultimately lack objectivity. Unfortunately, such a result is unavoidable, given the inherent biases that attend the study of a subject in limited form and from a particular vantage point. When scholars adopt an incomplete view and particular perspective, by definition, they approach the subject narrowly and from that point of view. Given that the scope and vantage point of the scholars are circumscribed, they cannot be expected to be comprehensive or objective in their study of the topic. For scholarship, objectivity is a principle that is at the very foundation of scientific inquiry (Kuhn 1962).

\section{AMA's Role and Responsibility}

Given its original purpose and desired role in marketing, the AMA should take a lead in offering a definition of marketing that reflects its modern practice and scholarship. This definition should capture the broadened scope and perspectives of marketing in society. It should also contemplate marketing's role and responsibility in society. As Lusch (2007, p. 267) describes,

[T] hree of the nine original purposes of the AMA, as stated in the 1937 constitution and bylaws of the AMA, were of a societal nature: (1) "to develop better public understanding and appreciation of marketing problems" (originally listed as Number 5), (2) "to study and discuss legislation and judicial deci- 
sions regarding marketing" (originally listed as Number 6), and (3) "to encourage and uphold sound, honest practices and to keep marketing work on a high ethical plane" (originally listed as Number 9).

With approximately 36,000 members and representing marketing managers, marketing researchers, academics, and students, the AMA desires to play an important and influential role in marketing scholarship and practice. Few in marketing are not familiar with AMA journals, conferences, and other activities. Many attend AMA conferences, publish in AMA journals, are members of its special interest groups, and have provided service to it. As a professional association, the AMA also positions itself as a "thought leader" and seeks to be a "leading indicator" of the marketing's direction and progress.

\section{Conclusion}

The contributions in the special section offer perspectives and insights as to why marketing should adopt a more comprehensive and pluralistic definition and consider its role and responsibility in society. I encourage the AMA to study these perspectives and insights and to adopt the wisdom and vision of those who have graciously provided them.

\section{Post Date}

As this special issue goes to press, following a newly adopted process by the AMA in May 2006 for review and revision of AMA definitions and after widespread solicitation and consideration of input and surveys of association members, an ad hoc subcommittee of the AMA Governance Committee submitted the following definition for consideration by the board of directors of the AMA:

Marketing is the activity, conducted by organizations and individuals, that operates through a set of institutions and processes for creating, communicating, delivering, and exchanging market offerings that have value for customers, clients, marketers, and society at large.

After formal consideration of the new definition in June 2007, the board failed to approve the recommended definition, providing comments for changes and requesting that the subcommittee resubmit a revised definition for further consideration. The subcommittee subsequently revised its original revision and submitted the revised version to the board. Before its deadline of June 30, the board did not reach a quorum of votes on a resolution that asked whether to adopt the subcommittee's resubmission. Thus, as of July 1, 2007, the 2004 AMA definition remains AMA's official definition of marketing.

\section{References}

AMA (1937), American Marketing Association: An Association for the Advancement of Science in Marketing: Proposal for Constitution and By-Laws. Chicago: AMA.

AMA Committee on Definitions (1960), Marketing Definitions: A Glossary of Marketing Terms. Chicago: AMA.

Anderson, Paul F. (1983), "Marketing, Scientific Progress, and Scientific Method," Journal of Marketing, 47 (Fall), 18-31.
Bartels, Robert (1983), "Is Marketing Defaulting Its Responsibilities," Journal of Marketing, 47 (Fall), 32-35.

Bazerman, Max H. (2001), "Consumer Research for Consumers," Journal of Consumer Research, 27 (4), 499-504.

Dunlap, Dennis L. (2006), Discussion at 2006 AMA Winter Educators' Conference, St. Petersburg, FL (February 17).

Grove, Stephen J., Joby John, and Raymond P. Fisk (2006), "Back to the Future: Putting People Back in Marketing," in Does Marketing Need Reform? Fresh Perspectives on the Future, Jagdish N. Sheth and Rajendra S. Sisodia, eds. Armonk, NY: M.E. Sharpe, 306-311.

Gundlach, Gregory T. (2005), "The American Marketing Association's New Definition of Marketing: Perspectives on Its Implications for Scholarship and the Role and Responsibility of Marketing and Society," in 2005 Marketing and Public Policy Conference Proceedings, Vol. 15, Jeff Langenderfer, Don Lloyd Cook, and Jerome D. Williams, eds. Chicago: AMA, $1-3$.

(2006), "Whither 'Marketing'? Commentary on the American Marketing Association's New Definition of Marketing," in Does Marketing Need Reform? Fresh Perspectives on the Future, Jagdish N. Sheth and Rajendra S. Sisodia, eds. Armonk, NY: M.E. Sharpe, 105-108.

—, Lauren G. Block, and William L. Wilkie, eds. (2007), Explorations of Marketing in Society. Mason, OH: Thomson Learning Systems.

Hunt, Shelby D. (2007), “A Responsibilities Framework for Marketing as a Professional Discipline," Journal of Public Policy \& Marketing, 26 (Fall), 277-83.

Keefe, Lisa M. (2004), "What Is the Meaning of Marketing?" Marketing News, (September 15), 17-18.

Kotler, Philip and Gary Armstrong (2001), Principles of Marketing. Upper Saddle River, NJ: Prentice Hall.

Kuhn, Thomas (1962), The Structure of Scientific Revolutions. Chicago: University of Chicago.

Laczniak, Gene R. (2006), "Some Societal and Ethical Dimensions of the Service-Dominant Logic Perspective of Marketing," in The Service-Dominant Logic of Marketing, Robert F. Lusch and Stephen L. Vargo, eds. Armonk, NY: M.E. Sharpe, 279-85.

Lehmann, Donald R. (2006), "More Dominant Logic for Marketing," in The Service-Dominant Logic of Marketing, Robert F. Lusch and Stephen L. Vargo, eds. Armonk, NY: M.E. Sharpe, 296-301.

Levy, Sidney J. (2006), "How New, How Dominant," in The Service-Dominant Logic of Marketing, Robert F. Lusch and Stephen L. Vargo, eds. Armonk, NY: M.E. Sharpe, 57-64.

Lusch, Robert F. (2007), "Marketing's Evolving Identity: Defining Our Future," Journal of Public Policy \& Marketing, 26 (Fall), 261-68.

- and Stephen L. Vargo, eds. (2006), The Service-Dominant Logic of Marketing. Armonk, NY: M.E. Sharpe.

Lynn, Barry C. (2005), End of the Line: The Rise and Coming Fall of the Global Corporation. New York: Doubleday.

Mick, David Glen (2006), "Meaning and Mattering Through Transformative Consumer Research," presidential address to the Association for Consumer Research, in Advances in Consumer Research, Vol. 33, Cornelia Pechmann and Linda L. Price, eds. Provo, UT: Association for Consumer Research, $1-4$. 
(2007), "The End(s) of Marketing and the Neglect of Moral Responsibility by the American Marketing Association," Journal of Public Policy \& Marketing, 26 (Fall), 289-92.

Ringold, Debra Jones and Barton A. Weitz (2007), "The American Marketing Association Definition of Marketing: Moving from Lagging to Leading Indicator," Journal of Public Policy \& Marketing, 26 (Fall), 251-60.

Sheth, Jagdish N. and Ragendra S. Sisodia, eds. (2006), Does Marketing Need Reform? Fresh Perspectives on the Future. Armonk, NY: M.E. Sharpe.

and Can Ulsay (2007), "Implications of the Revised Definition of Marketing: From Exchange to Value Creation," Journal of Public Policy \& Marketing, 26 (Fall), 302-307.

Shultz, Clifford J., II (2007), "Marketing as Constructive Engagement: A Post-AMA Synthesis," Journal of Public Policy \& Marketing, 26 (Fall), 293-301.

Tucker, W.T. (1974), "Future Directions in Marketing Theory," Journal of Marketing, 38 (April), 30-35.

Vargo, Stephen L. and Robert F. Lusch (2004), "Evolving to a New Dominant Logic for Marketing," Journal of Marketing, 68 (January), 1-17.
Wilkie, William L. (2006), "The World of Marketing Thought: Where Are We Heading?" in Does Marketing Need Reform? Fresh Perspectives on the Future, Jagdish N. Sheth and Rajendra S. Sisodia, eds. Armonk, NY: M.E. Sharpe, 239-247.

and Elizabeth S. Moore (1999), "Marketing's Contributions to Society," Journal of Marketing, 62 (Special Issue), 198-218.

and - (2003), "Scholarly Research in Marketing: Exploring the "4 Eras' of Thought Development," Journal of Public Policy \& Marketing, 22 (Fall), 116-46.

and (2006), "Examining Marketing Scholarship and the Service-Dominant Logic," in The Service-Dominant Logic of Marketing, Robert F. Lusch and Stephen L. Vargo, eds. Armonk, NY: M.E. Sharpe, 266-78.

and - (2007), "What Does the Definition of Marketing Tell Us About Ourselves?” Journal of Public Policy \& Marketing, 26 (Fall), 269-76.

Zinkhan, George M. and Brian C. Williams (2007), "The New American Marketing Association Definition of Marketing: An Alternative Assessment," Journal of Public Policy \& Marketing, 26 (Fall), 284-88. 
Copyright of Journal of Public Policy \& Marketing is the property of American Marketing Association and its content may not be copied or emailed to multiple sites or posted to a listserv without the copyright holder's express written permission. However, users may print, download, or email articles for individual use. 